\title{
Skeletal microenvironment system utilising bovine bone scaffold co-cultured with human osteoblasts and osteoclast-like cells
}

\author{
JAMES JAM JOLLY ${ }^{1}$, NUR FARHANA MOHD FOZI ${ }^{1}$, KOK-YONG CHIN ${ }^{1,2}$, SOK KUAN WONG ${ }^{1}$, \\ KIEN HUI CHUA $^{1}$, EKRAM ALIAS ${ }^{3}$, NUR SABARIAH ADNAN ${ }^{1}$ and SOELAIMAN IMA-NIRWANA ${ }^{1}$ \\ ${ }^{1}$ Department of Pharmacology, Faculty of Medicine, Pusat Perubatan Universiti Kebangsaan Malaysia, Cheras, \\ Wilayah Persekutuan Kuala Lumpur 56000, Malaysia; ${ }^{2}$ State Key Laboratory of Oncogenes and Related Genes, \\ Renji-Med X Clinical Stem Cell Research Center, Department of Urology, Ren Ji Hospital, School of Medicine, \\ Shanghai Jiao Tong University, Shanghai 201112, P.R. China; ${ }^{3}$ Department of Physiology, Faculty of Medicine, \\ Pusat Perubatan Universiti Kebangsaan Malaysia, Cheras, Wilayah Persekutuan Kuala Lumpur 56000, Malaysia
}

Received March 13, 2020; Accepted April 6, 2021

DOI: 10.3892/etm.2021.10112

\begin{abstract}
A three-dimensional ex vivo bone cell culture system mimicking the skeletal system is useful for bone tissue engineering and as drug discovery platforms. The present study aimed to establish a three-dimensional skeletal culture system using native bovine bone scaffolds and human bone cells. Bovine bone scaffolds were cultured with human foetal osteoblasts 1.19 and human peripheral blood mononuclear cells for 21 days under standard culture conditions. The following groups were established: Decalcified unseeded bone scaffold (DUBS) as baseline control, decalcified seeded bone scaffold (DSBS) to mimic osteoporosis condition and undecalcified seeded bone scaffold to mimic normal condition. The scaffold's porosity and cell attachment on the scaffolds were determined using scanning electron microscopy. Histological evaluation was used to examine changes in trabecular bone structure. Dual-energy X-ray absorptiometry analysis was performed to determine the bone mineral density (BMD) and bone mineral content (BMC) of the scaffolds. A compression test was performed to examine the total biomechanical strength of the scaffolds. The trabecular thickness and number increased, while the trabecular separationwas reduced slightly in DSBS than in DUBS ( $\mathrm{P}>0.05)$. The BMD and BMC increased significantly $(\mathrm{P}<0.05)$, while the compressive strength only increased slightly in DSBS than in DUBS $(\mathrm{P}>0.05)$. In conclusion, the ex vivo skeletal microenvironment comprising native bovine bone scaffolds seeded with bone cells is structurally,
\end{abstract}

Correspondence to: Professor Soelaiman Ima-Nirwana, Department of Pharmacology, Faculty of Medicine, Pusat Perubatan Universiti Kebangsaan Malaysia, Level 17, Preclinical Building, Jalan Yaacob Latif, Bandar Tun Razak, Cheras, Wilayah Persekutuan Kuala Lumpur 56000, Malaysia

E-mail:imasoel@ppukm.ukm.edu.my

Key words: drug screening, in vitro, macrophage, skeleton, osteoporosis functionally and mechanically comparable with natural bone. This system may be used as a platform to understand bone physiology and screen for potential drug candidates.

\section{Introduction}

Bone is a complex natural nanocomposite and growing tissue made up mostly of collagen and nano-hydroxyapatite (1-3). Bone serves as a protective and supportive framework for the body, as well as a reservoir for essential minerals and production site of blood cells (3). Numerous attempts have been made to design an artificial scaffold that is homogeneous and biocompatible for in vitro regeneration of new bone tissues $(4,5)$. A well-designed scaffold derived from natural or synthetic polymer must fulfill specific requirements to support cell growth (6-9). First, the scaffold must be osteoconductive, allowing bone cells to attach to and proliferate on its surface (10-13). The scaffold must also be biocompatible, allowing normal cellular activity without eliciting any harmful effects on the cells $(10,14)$. The combination of these two properties will allow cell proliferation and migration to the inner scaffold and deposition of the bone matrix $(4,6)$. Thus, the newly deposited mineral and matrix should enhance the scaffold biomechanically. Apart from its application in tissue regeneration, a three-dimensional in vitro bone cell system that mimics the in vivo bone microenvironment would be useful in basic science research of the skeletal system, as well as in testing of osteo-reactive compounds in drug development.

Commonly used synthetic bone scaffold materials include polymers $(11,12,15-17)$, bioceramics (17-20) and hydroxyapatite $(21,22)$. However, currently available synthetic scaffolds do not match the anatomical and physiological structures of normal bone. For instance, collagen-based scaffold does not have the hydroxyapatite mineral component, which is present in bone. The commonly used hydroxyapatite-based scaffold does not have a collagenous matrix, which may retard the growth of bone cells. The absence of either element in the scaffold reduces its biosimilarity with natural bone. Therefore, scaffolds derived from native/natural bone have been proposed as alternatives to synthetic ones due to their 
high biosimilarity (23). These scaffolds have the chemical and physical characteristics of natural bone. In the present study, bovine bones were used as the scaffold material. Studies have indicated that bovine bone as a block or as processed particles has high biocompatibility and osteoconductivity to osteoblasts and mesenchymal stem cells (24-26). In particular, bovine bone enhances the differentiation of osteoblast-like cells compared with hydroxyapatite (26).

The present study aimed to establish a static three-dimensional bone culture system consisting of the native bovine bone scaffold and human precursors of osteoblasts and osteoclasts. Bovine bones were obtained from waste products of the meat industry. The trabecular bone section was used, as its porous structure provides a large surface-to-volume ratio for the attachment of bone cells. The trabecular bone typically undergoes higher remodelling rate than the compact bone in vivo, and thus, changes in bone microstructure, cellular content and metabolic activity may occur within a shorter time (27). The biocompatibility of the bone scaffold was examined by assessing the proliferation of bone cells on its surface and their activities. Cells were observed to proliferate, remineralise and alter the mechanical properties of a biocompatible scaffold.

\section{Materials and methods}

Processing of bone scaffolds. Bone pieces were cut from the metaphysis of the bovine trabecular bone. The pieces were sectioned into $10 \mathrm{~mm}$ x $10 \mathrm{~mm}$ x $5 \mathrm{~mm}$ blocks by using a bone sawing machine (JG210A; Ahnaz Enterprise). All bone samples were immersed in $100 \%$ ethyl alcohol for $4 \mathrm{~h}$ to remove fat. The bone samples were decalcified by incubation in $0.6 \mathrm{~N}$ hydrochloric acid for 3 days at room temperature. The scaffolds were rinsed with sodium phosphate buffer $(\mathrm{pH} 7.4)$ to eliminate residual acid before being frozen at $-80^{\circ} \mathrm{C}$ for 2 weeks. The scaffolds were then freeze dried (FreeZone; Labconco Corp.) for 3 days and autoclaved prior to use.

Bone scaffold treatments. The porosity of the scaffold was characterised using a scanning electron microscope (JEOL USA, Inc.). Only bone scaffolds with an average pore size of $>350 \mu \mathrm{m}$ were used. The bone scaffolds were randomly subjected to three different treatments ( $n=4 /$ group): i) Decalcified unseeded bone scaffold (DUBS) group - decalcified but not seeded with bone cells, for use as a baseline control; ii) decalcified seeded bone scaffold (DSBS) group - decalcified and seeded with bone cells to mimic osteoporotic bone; and iii) undecalcified seeded bone scaffold (USBS) group - undecalcified but seeded with bone cells to mimic normal bone (normal control) (Table I).

\section{Establishment of osteoblast/osteoclast co-culture}

Human foetal osteoblast (hFOB) culture. The cell line hFOB 1.19 [American Type Culture Collection (ATCC) ${ }^{\circledR}$ CRL-11372 ${ }^{\mathrm{TM}}$; ATCC] was expanded in a T175 $\left(6,000 / \mathrm{cm}^{2}\right)$ culture flask by using Dulbecco's modified Eagle's medium/nutrient mixture F-12 medium (DMEM/F-12; Thermo Fisher Scientific, Inc.) with 5\% FBS (Thermo Fisher Scientific, Inc.) at $34^{\circ} \mathrm{C}$ under $5 \% \mathrm{CO}_{2}$ according to ATCC recommendations. Healthy cells between passages 6 and 8 , which exhibited $90 \%$ confluency on day 3 , were selected for co-culture with peripheral blood mononuclear cells (PBMNCs).

Isolation of PBMNCS. PBMNCs were obtained from blood collected using EDTA-coated tubes via venipuncture from five volunteers (three males and two females, aged 18-40 years) without any underlying medical problems. The protocol was reviewed and approved by the Human Research Ethics Committee of Universiti Kebangsaan Malaysia (Kuala Lumpur, Malaysia; approval code, UKM 1.5.3.5/244/FF-2014-187). Ficoll-Paque (Merck KGaA) was used to isolate PBMNCs within $1 \mathrm{~h}$ after blood collection.

Osteoblast/osteoclast co-culture procedures. Osteoblast/osteoclast co-culture procedures were performed as described previously with certain modifications (28). Approximately $2 \times 10^{6}$ hFOB 1.19 cells, harvested from a T175 culture flask 3 days after seeding, were mixed with $2 \mathrm{ml}$ human plasma and seeded on one scaffold. The plasma was obtained from the subjects who donated PBMNCs. Human plasma served as the transport medium for delivering nutrients from the culture medium to osteoblasts. The plasma formed a layer of fibrin gel, entrapping osteoblasts onto the scaffold surface. The use of fibrin to entrap osteoblast onto the scaffold was modified from a previous study (29). The hFOB 1.19 cells were cultured on the bone scaffold for 3 days to allow the deposition of collagen and calcium. A well formed by agarose gel was used to hold the scaffold in place and allow successful entrapment of cells. hFOB 1.19 cells were co-cultured with PBMNCs by adding the latter directly into the complete culture medium of DMEM/F-12 with 5\% FBS at the ratio of 2:1 (1x10 $10^{6}$ osteoblasts and $\left.5 \times 10^{5} \mathrm{PBMNCs}\right)$. The scaffolds were then maintained for 21 days at $37^{\circ} \mathrm{C}$ under $95 \%$ humidity and $5 \%$ carbon dioxide and then subjected to the analyses. The time window was selected because hFOB 1.19 cells take 21 days to mineralise (30). The media were replaced every two days. These co-culture procedures are illustrated in Fig. 1.

Bone scanning electron microscopy (SEM) analysis. After 21 days of treatment, cell attachment was observed using a scanning electron microscope (JEOL USA Inc.). Prior to SEM analysis, the bone scaffolds were fixed with $2.5 \%$ glutaraldehyde for $30 \mathrm{~min}$ at $4^{\circ} \mathrm{C}$. The scaffolds were dehydrated in graded alcohols until the maximum dehydration point was reached and finally sputter-coated with gold.

Bone histomorphometric analyses. Bone structural histomorphometric analysis was performed on the scaffolds. The scaffolds were fixed with neutral buffered formalin $(24 \mathrm{~h}$ at $4^{\circ} \mathrm{C}$ ), dehydrated in graded ethanol solutions, embedded in polymethyl methacrylate (Polysciences) and cut longitudinally into $5-\mu \mathrm{m}$ sections by using a microtome (RM2235; Leica Microsystems). The sections were stained using the von Kossa method (31). The histology slides were analysed using an image analyser (Eclipse 80i; Nikon Corp.) with automated image analysis software (Image Pro-Plus version 7.0; Media Cybernetics, Inc.). The structural parameters determined included trabecular bone thickness (Tb.Th; units, $\mu \mathrm{m}$ ), trabecular bone number (Tb.N; units, $1 / \mu \mathrm{m})$ and trabecular bone separation (Tb.S; unit, $\mu \mathrm{m}$ ). 


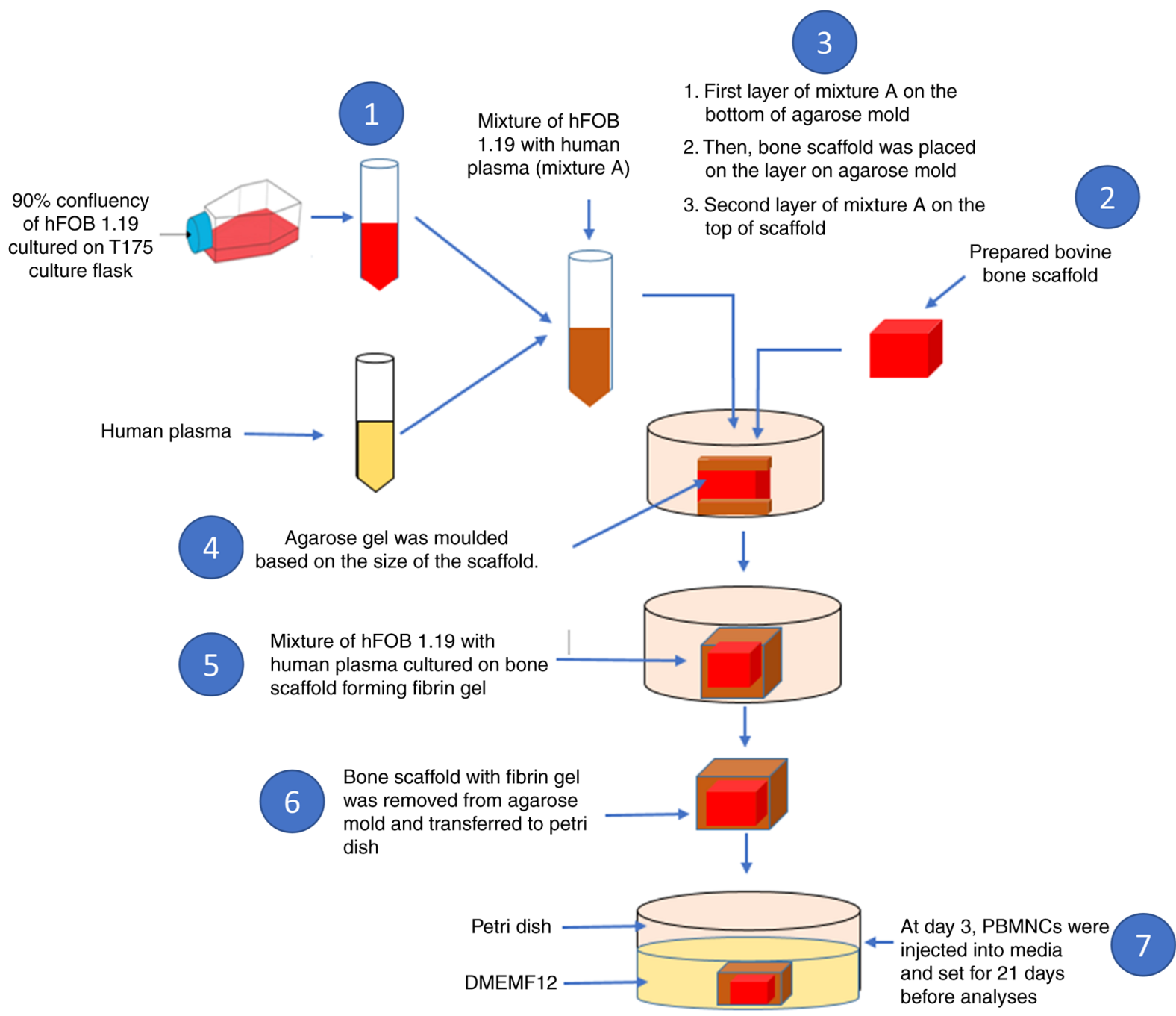

Figure 1. Preparation of the static human osteoblast-osteoclast three-dimensional bone cells co-culture system according to the following steps: 1 , hFOB 1.19 cells cultured in a flask were mixed with human plasma to form mixture A; 2 , a standardised bone scaffold was prepared from the bovine trabecular bone; 3 , a layer of mixture A was poured into the agarose mould. After it was hardened, the bone scaffold was placed on the top of the layer. Mixture A was poured onto the scaffold forming the second layer; 4 , the mould was modified to allow mixture A to be poured at the four sides of the bone scaffold; 5 , the fibrin formed trapped the cells on the surface of the scaffold; 6 , the bone scaffold with fibrin gel was transferred from the agarose mould to the Petri dish; 7, the bone scaffold with cells was cultured in DMEM-F12. On day 3 of culture, PBMCs were injected into the media. The bone scaffold was continued to be cultured for 21 days prior to analysis. PBMCs, peripheral blood mononuclear cells; hFOB, human foetal osteoblasts.

Table I. Bone scaffold models used in the different experimental groups of the present study.

\begin{tabular}{ll}
\hline Treatment & \multicolumn{1}{c}{ Group } \\
\hline Decalcified unseeded bone scaffold & Baseline \\
Decalcified seeded bone scaffold & Osteoporotic bone \\
Undecalcified seeded bone scaffold & Normal bone \\
\hline
\end{tabular}

Bone dual-energy X-ray absorptiometry (DXA) analyses. Bone mineral density and content were evaluated using a QDR 4500 DXA machine (Hologic Inc.). The whole scaffold was set as the region of interest and the bone mineral density (BMD) and content (BMC) were obtained.

Bone mechanical strength analysis. Bone biomechanical strength was evaluated by a compression test using a universal testing machine (Autograph AGS-X 500N; Shimadzu). The compression load was applied at $10 \mathrm{~mm} / \mathrm{min}$ onto the surface of the scaffold until it became fractured. The mechanical parameters determined were the ultimate compressive strength (unit: N). Trapezium Lite X software version 1.0 (Shimadzu) was used to analyse the results.

Statistical analysis. All statistical analyses were performed using SPSS version 20 software (IBM Corp.). One-way ANOVA with Tukey's post hoc test was used to identify significant differences among treatment groups. Values are expressed as the mean \pm standard error of the mean. $\mathrm{P}<0.05$ was considered to indicate a statistically significant difference.

\section{Results}

Proliferation of bone cells on the bovine scaffolds. The SEM images revealed a porous surface in the DUBS group, which represented the bare trabecular bone (Fig. 2A). The 


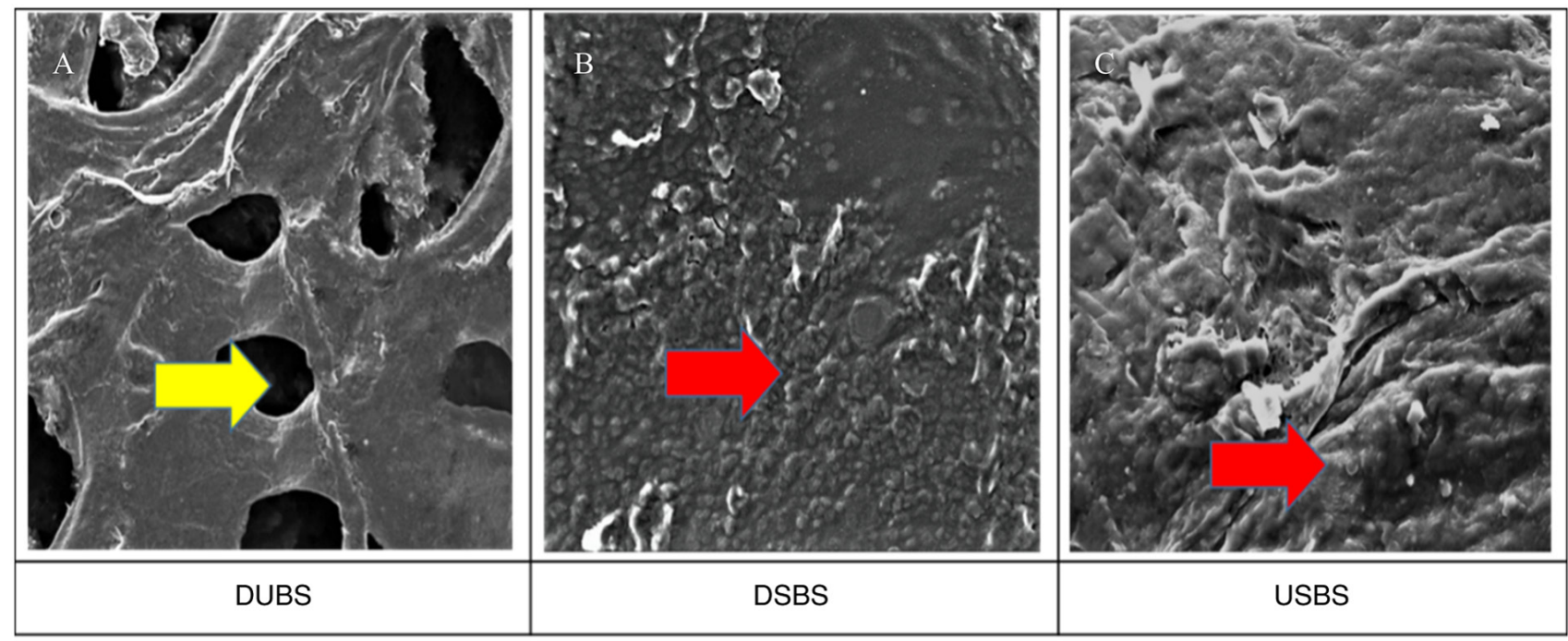

Figure 2. Scanning electron microscopy analysis of bone scaffolds post-treatment. (A) DUBS, (B) DSBS and (C) USBS. The yellow arrow indicates empty trabecular spaces and the red arrow indicates extracellular matrix (magnification, x300). DUBS, decalcified unseeded bone scaffold; DSBS, decalcified seeded bone scaffold; USBS, undecalcified seeded bone scaffold.

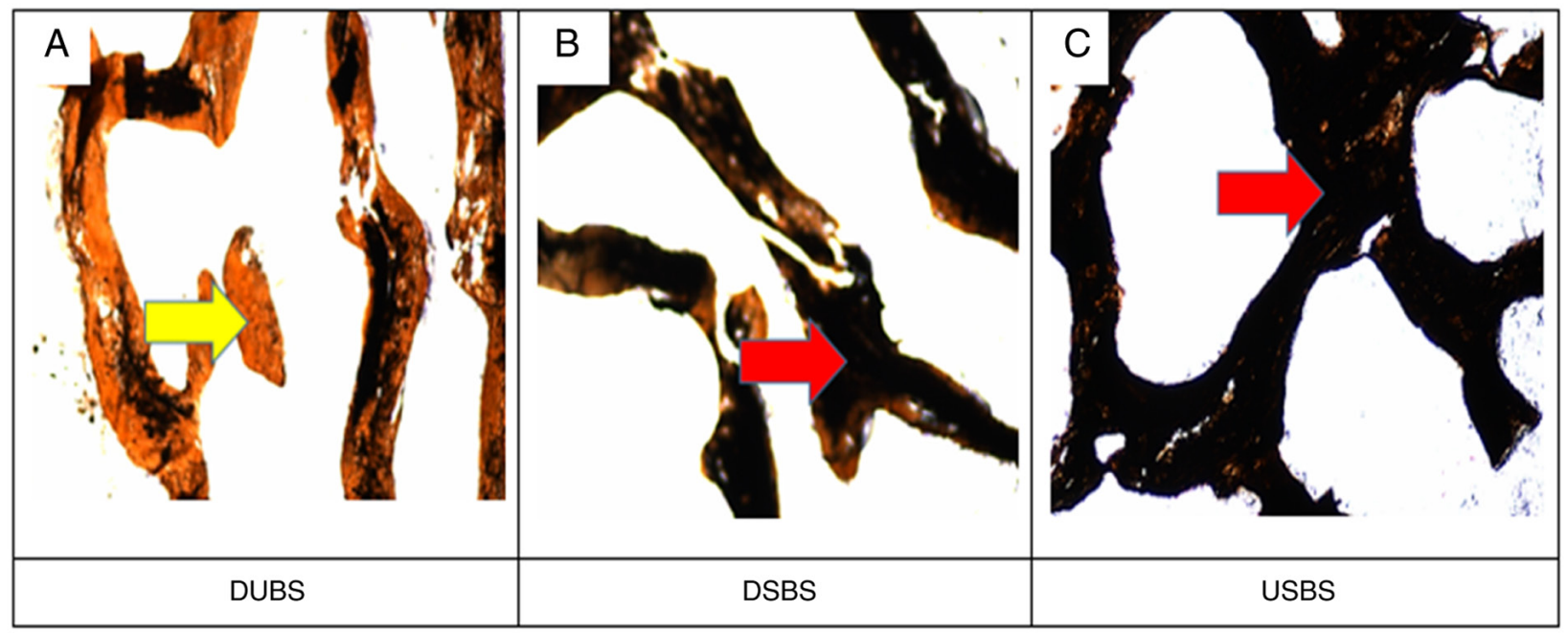

Figure 3. Histomorphometric observation of bone scaffolds post-treatment (von Kossa; magnification, x200). Images displaying the trabecular structure of (A) DUBS, (B) DSBS and (C) USBS. The yellow arrow indicates trabecula with less deposition of calcium (brownish colour) and the red arrows indicate high deposition of calcium (black colour). DUBS, decalcified unseeded bone scaffold; DSBS, decalcified seeded bone scaffold; USBS, undecalcified seeded bone scaffold.

DSBS was covered by a flat and coarse matrix, suggesting successful colonisation of osteoblasts on the bone surface (Fig. 2B). A matrix was also formed on the surface of the USBS, indicating the proper proliferation and functioning of the cells. The matrix on the USBS appeared wrinkled and folded (Fig. 2C).

Mineralisation of the bone scaffolds by bone cells. Von Kossa staining was used to visualise the degree of mineralisation of the bone scaffolds. The intensity of staining was in the following order: USBS > DSBS > DUBS (Fig. 3). A slight increase in Tb.Th (Fig. 4A) and Tb.N (Fig. 4B), as well as a decrease in Tb.S (Fig. 4C) were observed in the DSBS group than in the DUBS group, but the difference was not significant $(P>0.05)$. The USBS group had significantly higher values for
Tb.Th and Tb.N than the DUBS and DSBS groups, as well as a significantly lower value for Tb.S than the DUBS group $(\mathrm{P}<0.05)$.

Mineral density and content of the scaffold. After cell seeding, the BMD and BMC values of the USBS group were significantly higher than those of the DSBS and DUBS groups $(\mathrm{P}<0.05)$. Furthermore, the DSBS group had significantly higher BMD and BMC values compared with those in the DUBS group $(\mathrm{P}<0.05$; Fig. 5).

Biomechanical strength analysis of bone scaffolds. After cell seeding, the load in the DSBS group was slightly increased compared with in the DUBS group, but the difference was not significant $(\mathrm{P}>0.05)$. However, the load in the USBS group was 

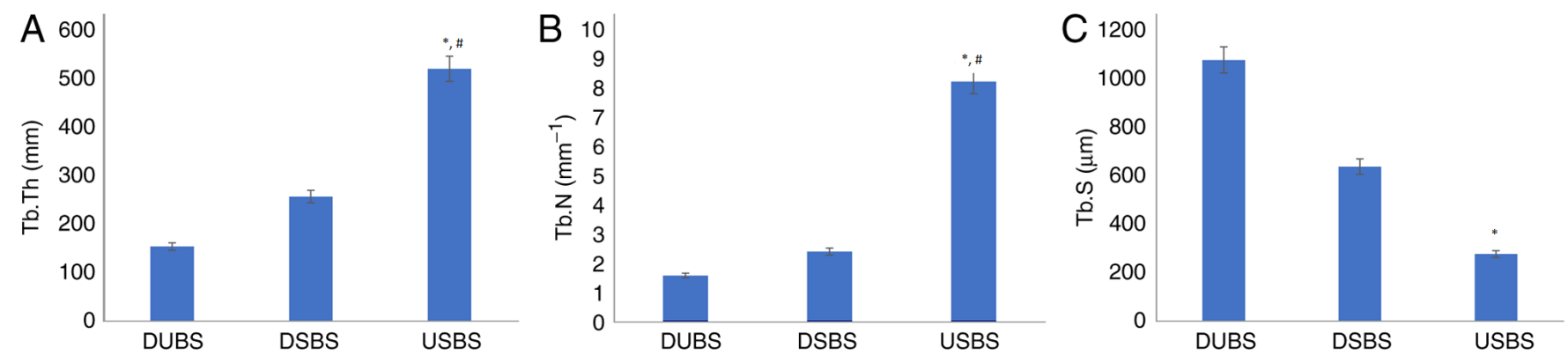

Figure 4. Quantitative histomorphometric analysis of bone scaffolds post-treatment. (A) Tb.Th, (B) Tb.N and (C) Tb.S of DUBS, DSBS and USBS. Tb.Th and Tb.N were significantly higher in USBS than in DUBS and DSBS. Tb.S was significantly lower in USBS than in DUBS. Values are expressed as mean \pm standard error of the mean. ${ }^{~} \mathrm{P}<0.05$ vs. DUBS; ${ }^{\mathrm{P}} \mathrm{P}<0.05$ vs. DSBS. Tb.Th, trabecular thickness; $\mathrm{Tb} . \mathrm{N}$, trabecular number; Tb.S, trabecular separation; DUBS, decalcified unseeded bone scaffold; DSBS, decalcified seeded bone scaffold; USBS, undecalcified seeded bone scaffold.

A

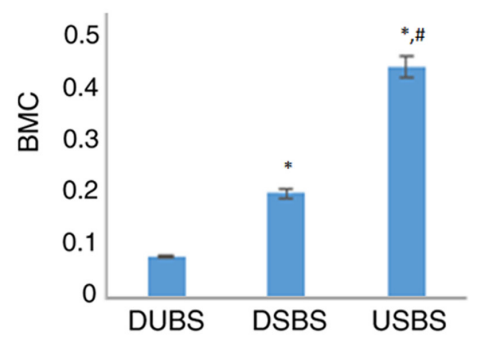

B

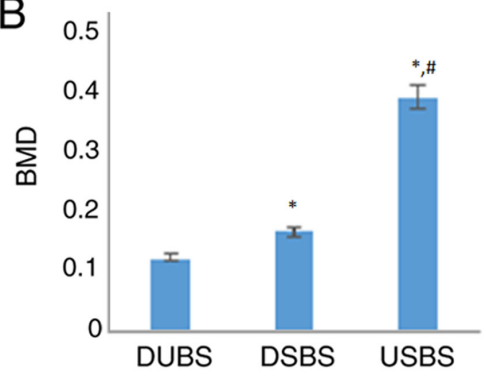

Figure 5. Dual-energy X-ray absorptiometry analysis results of bone scaffolds post-treatment. (A) BMC and (B) BMD of DUBS, DSBS and USBS. Values are expressed as mean \pm standard error of the mean. BMC and BMD were higher in DSBS than in DUBS, as well as in USBS than in DUBS and DSBS. ${ }^{*}<<0.05$ vs. DUBS; ${ }^{\mathrm{P}} \mathrm{P}<0.05$ vs. DSBS. DUBS, decalcified unseeded bone scaffold; DSBS, decalcified seeded bone scaffold; USBS, undecalcified seeded bone scaffold; BMD, bone mineral density; BMC, bone mineral content.

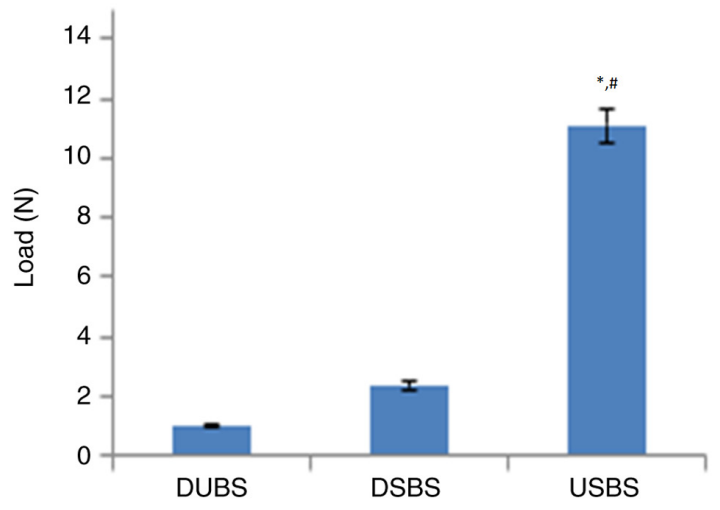

Figure 6. Mechanical strength analysis of bone scaffolds post-treatment. of DUBS, DSBS and USBS. The load value was higher in USBS than in DUBS and DSBS. Values are expressed as mean \pm standard error of the mean. "P<0.05 vs. DUBS; ${ }^{\# P}<0.05$ vs. DSBS. DUBS, decalcified unseeded bone scaffold; DSBS, decalcified seeded bone scaffold; USBS, undecalcified seeded bone scaffold.

significantly higher than that in the DSBS or the DUBS group $(\mathrm{P}<0.05$; Fig. 6).

\section{Discussion}

In the present study, the properties of a native bovine bone scaffold cultured with hFOB 1.19 osteoblasts and PBMNCs as precursors of osteoclasts were studied. In this experiment, a co-culture system of hFOB 1.19 osteoblasts and PBMNCs (as precursors for osteoclasts) was used, as osteoblasts and osteoclasts are responsible for bone formation and bone degradation in the endogenous skeletal microenvironment (32). Since there is no osteoclast cell line available, PBMNCs were differentiated into osteoclast-like cells as the experimental model of osteoclasts. Osteoblasts have a vital role by secreting cytokines such as macrophage colony-stimulating factor and tumour necrosis factor ligand superfamily member 11 , which in turn induce the formation and maturation of osteoclasts $(22,33)$. Matured osteoclasts resorb old damaged bone (34) and produce tartrate-resistance acid phosphatase, an enzyme responsible for biological mechanisms, such as collagen synthesis, skeleton development and bone mineralisation (22). The interplay between these bone cells is important to ensure the continuity of the bone remodelling mechanism.

In the present study, the biocompatibility of the scaffold for co-culture of human cells was assessed via cell proliferation and function. The present observations indicated that the bone cells proliferated and synthesised a layer of extracellular matrix on the surface of the DSBS and USBS. This approach in assessing the biocompatibility of the native bone scaffold has been adopted by other researchers (35). The observation suggested that the scaffold supported the viability and function of bone cells. The interconnected porous structure of a scaffold ensures a good passage for nutrients and provides a favourable biological environment for cell attachment and biomineralisation (36). The pore size of $>350 \mu \mathrm{m}$ was set as the criterion for selecting the bone scaffold, as it promotes cell migration and prevents cell aggregation along the edges of the 
scaffolds (8). A study by Sladkova et al (37) has indicated that bone cancellous scaffolds with larger pores facilitate penetration of the cells, but scaffolds with smaller pores allow cell aggregates and promote osteogenic differentiation of stem cells.

The structural histomorphometric evaluation indicated the mineralisation of the trabeculae and increased trabecular thickness and number in the USBS group compared with those in the DSBS and DUBS groups. It was thus hypothesized that the osteoblasts attached to the trabecular surfaces were fully functional and started to secrete bone matrix and mineralise it. The deposition of mineral was confirmed by DXA assessment, whereby the BMD and BMC of DSBS increased compared with those of the DUBS. A previous study implanted the native bone scaffold in rabbits, showing increased BMC and BMD (38). However, the present study showed that the increase in BMC and BMD was achieved in an in vitro environment. The demineralised scaffold with natural cross-linked collagen type I fibrils provides a template for mineral deposition (23). The mineral is deposited onto the collagenous matrix of the scaffold, indicating that the osteoblasts are committed to osteogenesis (39).

The mineralised matrix is expected to make the scaffolds stronger and more stable (23). In the present study, USBS endured a higher load during the compression test compared with the DSBS and DUBS, corresponding to the results regarding the BMD and BMC. However, the DSBS and DUBS sustained a similar load in the test. Considering that both of them are demineralised, we suggest that the amount of mineral newly deposited by the osteoblasts was not sufficient to cause a significant change in the mechanical properties of the scaffolds. The mechanical strength of a scaffold is important to maintain the spaces required for ingrowth of the cells, matrix production and new bone formation (10,40-42). The balance between porosity and mechanical strength is delicate, but a clear criterion exists for this ratio for a good scaffold (43). The mechanical strength should be similar to that of natural bone $(34,43,44)$.

The present study has several limitations. Cell viability and proliferation assessment using biochemical methods, such as MTT and flow cytometry, was not feasible due to the three-dimensional nature of the culture system. It was not possible to examine individual cell characteristics, as the cells were embedded in the matrix. However, SEM examination revealed that the cells were attached and were functioning on the scaffold by forming an extracellular matrix. The use of the static culture system may not be optimal for efficient delivery of nutrients into the scaffold. The use of a bioreactor is recommended to ensure homogeneous mineralisation and optimal supply of nutrients throughout the co-culture process. A bioreactor is a vessel used for biological reactions and culture of aerobic cells (45). This instrument was not used in the present study, as it was not available in our laboratory. All parameters were measured on day 21 only. A time-series approach should be considered in future studies to monitor changes in these variables. Future studies should also compare the biocompatibility and osteoconductivity of the scaffold designed to be composed of traditional synthetic scaffolds. Pre-treatment measurement of the BMC should be considered in future studies for better standardisation. Furthermore, future studies should also consider using an undecalcified, unseeded bone scaffold as a native bone control and comparing decalcified bone scaffolds seeded with osteoblasts, osteoclasts and both cell types together. Currently, a patent has been filed to use this scaffold system as an in vitro skeletal microenvironment for bone biology and drug screening studies (46).

In conclusion, in the present study, a static three-dimensional bone culture system using native bone scaffold derived from bovine trabecular bone and co-culture of hFOB 1.19 osteoblasts and PBMNCs was established. The cells grow on the native bone scaffold, as observed by scaffold surface assessment for cell attachment and also histological evaluation. Scaffold mineralisation, as illustrated by increases in BMC and BMD of DSBS compared with DUBS, indicated that the bone cells attached were fully functional. However, due to the short culture period, the slight improvement in biomechanical strength of the demineralised scaffold was not significant. Future research should consider prolonging the culture time and the use of a bioreactor for improving the three-dimensional culture system. This skeletal microenvironment system may be useful for understanding the bone remodelling process ex vivo and for testing agents for improving bone health.

\section{Acknowledgements}

The authors thank the following staff members of the Pharmacology Department, Faculty of Medicine, Universiti Kebangsaan Malaysia (Kuala Lumpur, Malaysia) for their technical assistance: Miss Nur Sabariah Adnan, Mrs. Nurul Hafizah Abas, Mrs. Juliana Abdul Hamid, Mr. Mohd Mustazil Mohd Noor, Mr. Azlan Mohd Arlamsyah and Mr. Fadhlullah Zuhair Japar Sidik.

\section{Funding}

Universiti Kebangsaan Malaysia funded this study (grant Laureate-003-2013).

\section{Availability of data and materials}

The datasets used and/or analyzed during the present study are available from the corresponding author on reasonable request.

\section{Authors' contributions}

JJJ drafted the manuscript. KHC, EA and SIN conceived the study, secured the funding and supervised the project. JJJ, NFMF and NSA performed the experiments. KYC, SKW and SIN contributed to the interpretation of data for the work, and critically reviewed and revised the manuscript. SIN gave the final approval of the version to be published. JJJ and SIN confirm the authenticity of all the raw data. All authors read and approved the final manuscript.

\section{Ethics approval and consent to participate}

The protocol of harvesting peripheral mononuclear cells was reviewed and approved by the Human Research Ethics Committee of Universiti Kebangsaan Malaysia (Kuala Lumpur, Malaysia; approval code, UKM 1.5.3.5/244/FF-2014-187). All 
subjects provided written informed consent prior to participating in the study.

\section{Patient consent for publication}

Not applicable.

\section{Competing interests}

The current scaffold design has been filed for a patent by SIN through the Centre for Collaborative Innovation, Universiti Kebangsaan Malaysia (reference no. PI2018701031). The authors declare that they have no competing interests.

\section{References}

1. Zahedi E, Ansari S, Wu BM, Bencharit S and Moshaverinia A Hydrogels in craniofacial tissue engineering. In: Biomaterials for Oral and Dental Tissue Engineering. Elsevier, pp47-64, 2018.

2. Jin H-H, Kim D-H, Kim T-W, Shin KK, Jung JS, Park HC and Yoon SY: In vivo evaluation of porous hydroxyapatite/chitosan-alginate composite scaffolds for bone tissue engineering. Int J Biol Macromol 51: 1079-1085, 2012.

3. Venkatesan J, Bhatnagar I, Manivasagan P, Kang K-H and Kim S-K: Alginate composites for bone tissue engineering: A review. Int J Biol Macromol 72: 269-281, 2015.

4. Karageorgiou V and Kaplan D: Porosity of 3D biomaterial scaffolds and osteogenesis. Biomaterials 26: 5474-5491, 2005.

5. LeGeros RZ: Properties of osteoconductive biomaterials: Calcium phosphates. Clin Orthop Relat Res 395: 81-98, 2002.

6. Wang H, Li Y, Zuo Y, Li J, Ma S and Cheng L: Biocompatibility and osteogenesis of biomimetic nano-hydroxyapatite/polyamide composite scaffolds for bone tissue engineering. Biomaterials 28 3338-3348, 2007.

7. Huh J, Lee J, Kim W, Yeo M and Kim G: Preparation and characterization of gelatin $/ \alpha$-TCP/SF biocomposite scaffold for bone tissue regeneration. Int J Biol Macromol 110: 488-496, 2018.

8. Murphy CM, Haugh MG and O'Brien FJ: The effect of mean pore size on cell attachment, proliferation and migration in collagen-glycosaminoglycan scaffolds for bone tissue engineering. Biomaterials 31: 461-466, 2010.

9. Vozzi G, Corallo C, Carta S, Fortina M, Gattazzo F, Galletti M and Giordano N: Collagen-gelatin-genipin-hydroxyapatite composite scaffolds colonized by human primary osteoblasts are suitable for bone tissue engineering applications: In vitro evidences. J Biomed Mater Res A 102: 1415-1421, 2014.

10. Hofmann S, Hagenmüller H, Koch AM, Müller R, Vunjak-Novakovic G, Kaplan DL, Merkle HP and Meinel L: Control of in vitro tissue-engineered bone-like structures using human mesenchymal stem cells and porous silk scaffolds. Biomaterials 28: 1152-1162, 2007.

11. Nam YS, Yoon JJ and Park TG: A novel fabrication method of macroporous biodegradable polymer scaffolds using gas foaming salt as a porogen additive. J Biomed Mater Res 53: 1-7, 2000.

12. Laurencin C, Lu H and Khan Y: Processing of polymer scaffolds: Polymer-ceramic composite foams. Tissue Eng Part C Methods: 705-714, 2002.

13. Lloyd AW: Interfacial bioengineering to enhance surface biocompatibility. Med Device Technol 13: 18-21, 2002.

14. Velasco MA, Narváez-Tovar CA and Garzón-Alvarado DA: Design, materials, and mechanobiology of biodegradable scaffolds for bone tissue engineering. Biomed Res Int 2015: 729076, 2015.

15. Ma PX and Zhang R: Microtubular architecture of biodegradable polymer scaffolds. J Biomed Mater Res 56: 469-477, 2001.

16. Levenberg S, Huang NF, Lavik E, Rogers AB, Itskovitz-Eldor J and Langer R: Differentiation of human embryonic stem cells on three-dimensional polymer scaffolds. Proc Natl Acad Sci USA 100: 12741-12746, 2003.

17. Rezwan K, Chen QZ,Blaker JJ and Boccaccini AR: Biodegradable and bioactive porous polymer/inorganic composite scaffolds for bone tissue engineering. Biomaterials 27: 3413-3431, 2006.

18. Guda T, Appleford M, Oh S and Ong JL: A cellular perspective to bioceramic scaffolds for bone tissue engineering: The state of the art. Curr Top Med Chem 8: 290-299, 2008
19. Pilliar RM, Filiaggi MJ, Wells JD, Grynpas MD and Kandel RA: Porous calcium polyphosphate scaffolds for bone substitute applications - in vitro characterization. Biomaterials 22: 963-972, 2001.

20. Rodrigues CV, Serricella P, Linhares AB, Guerdes RM, Borojevic R, Rossi MA, Duarte ME and Farina M: Characterization of a bovine collagen-hydroxyapatite composite scaffold for bone tissue engineering. Biomaterials 24: 4987-4997, 2003.

21. Zhao H, Ma L, Gao C and Shen J: Fabrication and properties of mineralized collagen-chitosan/hydroxyapatite scaffolds. Polym Adv Technol 19: 1590-1596, 2008.

22. Schönmeyr BH, Wong AK, Li S, Gewalli F, Cordiero PG and Mehrara BJ: Treatment of hydroxyapatite scaffolds with fibronectin and fetal calf serum increases osteoblast adhesion and proliferation in vitro. Plast Reconstr Surg 121: 751-762, 2008.

23. Polo-Corrales L, Latorre-Esteves $M$ and Ramirez-Vick JE: Scaffold design for bone regeneration. J Nanosci Nanotechnol 14: 15-56, 2014.

24. Silva GAB, Bertassoli BM, Sousa CA, Albergaria JD, de Paula RS and Jorge EC: Effects of strontium ranelate treatment on osteoblasts cultivated onto scaffolds of trabeculae bovine bone. J Bone Miner Metab 36: 73-86, 2018.

25. Shahabipour F, Mahdavi-Shahri N, Matin MM, Tavassoli A and Zebarjad SM: Scaffolds derived from cancellous bovine bone support mesenchymal stem cells' maintenance and growth. In Vitro Cell Dev Biol Anim 49: 440-448, 2013.

26. Mastrangelo F, Quaresima R, Grilli A, Tettamanti L, Vinci R, Sammartino G, Tetè S and Gherlone E: A comparison of bovine bone and hydroxyapatite scaffolds during initial bone regeneration: An in vitro evaluation. Implant Dent 22: 613-622, 2013.

27. Seibel MJ: Bone metabolism. In: Encyclopedic Reference of MolecularPharmacology. Springer, Berlin Heidelberg, Berlin, Heidelberg, pp190-197, 2004.

28. Jolly JJ, Chin KY, Farhana MFN, Alias E, Chua KH, Hasan WNW and Ima-Nirwana S: Optimization of the Static Human Osteoblast/Osteoclast Co-culture System. Iran J Med Sci 43: 208-213, 2018.

29. Sulaiman SB, Keong TK, Cheng CH, Saim AB and Idrus RB: Tricalcium phosphate/hydroxyapatite (TCP-HA) bone scaffold as potential candidate for the formation of tissue engineered bone. Indian J Med Res 137: 1093-1101, 2013.

30. Setzer B, Bächle M, Metzger MC and Kohal RJ: The gene-expression and phenotypic response of hFOB 1.19 osteoblasts to surface-modified titanium and zirconia. Biomaterials 30 : 979-990, 2009

31. Majeed SA, Mohamed N and Soelaiman I-N: Quantification of Bone Histomorphometric Parameters Using the Weibel Technique in Animals. Med Health 11: 278-288, 2016.

32. Siddiqui JA and Partridge NC: Physiological bone remodeling: Systemic regulation and growth factor involvement. Physiology (Bethesda) 31: 233-245, 2016.

33. Thomson RC, Yaszemski MJ, Powers JM and Mikos AG: Fabrication of biodegradable polymer scaffolds to engineer trabecular bone. J Biomater Sci Polym Ed 7: 23-38, 1995.

34. Salgado AJ, Coutinho OP and Reis RL: Bone tissue engineering: State of the art and future trends. Macromol Biosci 4: 743-765, 2004.

35. Rashmi RP, Pathak R, Amarpal, Aithal HP, Kinjavdekar P, Pawde AM, Tiwari AK, Sangeetha P, Tamilmahan P and Manzoor AB: Evaluation of tissue-engineered bone constructs using rabbit fetal osteoblasts on acellular bovine cancellous bone matrix. Vet World 10: 163-169, 2017.

36. Li Z, Ramay HR, Hauch KD, Xiao D and Zhang M: Chitosan-alginate hybrid scaffolds for bone tissue engineering. Biomaterials 26: 3919-3928, 2005.

37. Sladkova M, Cheng J, Palmer M, Chen S, Lin C, Xia W, Yu YE, Zhou B, Engqvist H and de Peppo GM: Comparison of decellularized cow and human bone for engineering bone grafts with human induced pluripotent stem cells. Tissue Eng Part A 25: 288-301, 2019.

38. Huang R-L, Tremp M, Ho C-K, Sun Y, Liu K and Li Q: Prefabrication of a functional bone graft with a pedicled periosteal flap as an in vivo bioreactor. Sci Rep 7: 18038, 2017.

39. Andric T, Taylor BL, Whittington AR and Freeman JW: Fabrication and Characterization of Three-Dimensional Electrospun Scaffolds for Bone Tissue Engineering. Regen Eng Transl Med 1: 32-41, 2015.

40. Liu X, Smith LA, Hu J and Ma PX: Biomimetic nanofibrous gelatin/apatite composite scaffolds for bone tissue engineering. Biomaterials 30: 2252-2258, 2009. 
41. Porter BD, Oldham JB, He SL, Zobitz ME, Payne RG, An KN, Currier BL, Mikos AG and Yaszemski MJ: Mechanical properties of a biodegradable bone regeneration scaffold. J Biomech Eng 122: 286-288, 2000.

42. Chu T-MG, Orton DG, Hollister SJ, Feinberg SE and Halloran JW: Mechanical and in vivo performance of hydroxyapatite implants with controlled architectures. Biomaterials 23: 1283-1293, 2002.

43. Hutmacher DW: Scaffolds in tissue engineering bone and cartilage. In: The Biomaterials. Silver Jubilee Compendium Elsevier, pp175-189, 2006.

44. Ma PX: Scaffolds for tissue fabrication. Mater Today 7: 30-40, 2004.
45. Gaspar DA, Gomide V and Monteiro FJ: The role of perfusion bioreactors in bone tissue engineering. Biomatter 2: 167-175, 2012.

46. Ima Soelaiman S, Chua KH, Alias E, Chin KY, Jolly JJ and Mohd Fozi NF: A Method Of Preparing A Cell-Scaffold Composite For In-Vitro Study Of Therapeutic Agents On Bone Disorders (Filing ID by Universiti Kebangsaan Malaysia: PI2018701031)

(i) (2) This work is licensed under a Creative Commons

cc) International (CC BY-NC-ND 4.0) License. 